\title{
Comparative analysis of two different models of swimming applied to pregnant rats born small for pregnant age
}

\author{
SILVANA B. CORVINO ${ }^{1}$, DÉBORA C. DAMASCENO ${ }^{1}$, YURI K. SINZATO ${ }^{1}$, ALINE O. NETTO ${ }^{1}$, \\ NATHÁLIA C.D. MACEDO ${ }^{1}$, ELENA ZAMBRANO ${ }^{2}$ and GUSTAVO T. VOLPATO ${ }^{1,3}$ \\ ${ }^{1}$ Laboratório de Pesquisa Experimental de Ginecologia e Obstetrícia, Faculdade de Medicina de Botucatu, \\ Universidade Estadual Paulista/UNESP, Distrito de Rubião Jr, s/n, 18618-970 Botucatu, SP, Brazil \\ ${ }^{2}$ Department of Reproductive Biology, Instituto Nacional de Ciencias Médicas y \\ Nutrición Salvador Zubirán, Cidade do México, 14080 México \\ ${ }^{3}$ Laboratório de Fisiologia de Sistemas e Toxicologia Reprodutiva, Instituto de Ciências Biológicas e da Saúde, \\ Universidade Federal de Mato Grosso/UFMT, Av. Valdon Varjão, 6390, 78600-000 Barra do Garças, MT, Brazil
}

Manuscript received on May 23, 2016; accepted for publication on September 7, 2016

\begin{abstract}
The aim of this study was to compare two models of swimming applied to pregnant rats born small for pregnancy age (SPA). Diabetes was chemically induced in adult female rats to develop an inadequate intrauterine environment, leading to birth of a SPA offspring. In adulthood, the female SPA rats were mated and submitted to different swimming programs. The exercise program 1 (Ex1) consisted of swimming for 15 minutes, followed by 15 minutes of rest and another 15 minutes of swimming, 3 days a week before and during pregnancy. Another program (Ex2) was applied during 60 minutes uninterrupted a day, 6 days/ week during pregnancy. The pregnant rats presented no interference on body weight and glycemia. The rats submitted to Ex2 model showed decreased insulin and blood glucose levels by oral glucose tolerance test, and reduction in area under curve values. The offspring from dams submitted to both exercise protocols presented an increased rate of newborns SPA. However, the offspring from Ex2 dams showed percentage twice higher of newborns SPA than Ex1 offspring. Our data suggests that continuous exercise of $60 \mathrm{~min} /$ day ameliorated the enhanced peripheral insulin sensitivity in growth-restricted females. However, this protocol employed at pregnancy leads to intrauterine growth restriction.
\end{abstract}

Key words: rats, diabetes, pregnancy, offspring, exercise.

\section{INTRODUCTION}

Human epidemiological (Ravelli et al. 1999, Roseboom et al. 1999) and experimental animal (Guzman et al. 2006, Nathanielsz 2006) studies have shown that an inappropriate intrauterine environment impairs fetal growth and development, and

Correspondence to: Débora Cristina Damasceno

E-mail: damascenofmb@gmail.com predisposes individuals to lifelong health problems. This effect is known as "fetal origins of adult diseases - FOAD". Today the concept of developmental origins of health and disease $(\mathrm{DOHaD})$ is better known than the FOAD, because it considers both fetal and neonatal period (development) and not only diseases but health. There is evidence that the nature of fetal programming is involved in many disease phenotypes, including those of 
successive generations (Barker 1997, KanakaGantenbein 2010, Hanson and Gluckman 2011). Several experimental models are performed to reproduce a uterus in suboptimal conditions aiming to understand the pathophysiological mechanisms involved in an unfavorable intrauterine environment (Fernandez-Twinn and Ozanne 2006, Aerts and Van Assche 2006, Zambrano 2009). These models are the use of glucocorticoids (Nyirenda et al. 1998), reduced blood flow by bilateral uterine artery ligation (Simmons 2001, Tran et al. 2013), chronic hypertension (Bassan et al. 2005), protein malnutrition (Zambran 2009, Dahri et al. 1991) and severe diabetes induction (Corvino et al. 2015a, b).

Studies showed that STZ-induced diabetic rats before pregnancy present high glycemia (>300mg/ $\mathrm{dL}$ - severe diabetes) and their offspring was born small for pregnancy age (SPA) due to an intrauterine growth restriction (IUGR) (Damasceno et al. 2011, 2013, Volpato et al. 2011).

The association of IUGR and increased risk of adult diabetes is observed in epidemiologic studies (Wolf 2003). The association between diet and insulin is, traditionally, the therapeutic resource most used to control blood glucose level. Physical exercise has been known for its role for controlling the glycemic level (Kim 2010). The correlation between the potential benefits and the risks of physical exercise during pregnancy is unclear. Previous studies performed in our laboratory demonstrated that swimming applied to severely diabetic rats during pregnancy contributed to an improved reproductive performance and maternal lipid metabolism (Volpato et al. 2006, 2009). For evaluation of swimming effect, using similar methodology of Volpato et al. (2009) on offspring born SPA from diabetic dams Corvino et al. (2015a) performed another study in our laboratory. The last authors showed that the swimming unchanged maternal weight gain and glycemia, but improved lipid metabolism and increased insulin sensitivity. These findings suggest beneficial results of this swimming program for maternal organism. However, it was verified an increased rate of offspring with SPA, demonstrating IUGR (Corvino et al. 2015a). This fact confirms that intensity, duration, type and period of swimming application are factors that may interfere on the embryo-fetal development. Therefore, considering the beneficial results for maternal organism but fetal impairment after implementation of swimming program during pregnancy, our research group developed another swimming program, which consisted of an exercise applied at intervals, fewer days in the week and prior training to pregnancy (Corvino et al. 2015b). In this study, the authors verified this swimming program caused intolerance glucose prevention, reduced general adiposity, increased relative weight of organ in maternal organism and offspring and increased rate of newborn classified as adequate for pregnancy age. We hypothesized that the characteristics of applied physical exercise, such as type, intensity and period of life, are essential factors to promote changes in the maternal intrauterine environment. Then, the objective of the present study was to compare the maternal outcomes of two different models of swimming applied to pregnant rats born small for pregnancy age.

\section{MATERIALS AND METHODS}

\section{ANIMALS}

The Animal Research Ethics Committee of the Botucatu Medical School_UNESP (Protocol CEEA 938/2012) approved the experimental protocols. Female and male Wistar rats (CEMIB - UNICAMP, Campinas - São Paulo State - Brazil) weighing approximately 200 grams (g) were housed in a certified animal care. Food and water were provided ad libitum. The rats were maintained on Laboratory of Experimental Research on Gynecology and Obstetrics under controlled conditions (temperature $22 \pm 2^{\circ} \mathrm{C}$, humidity $55 \pm 5 \%$ and $12 \mathrm{~h} \mathrm{light/dark} \mathrm{cycle)}$. 
DIABETES INDUCTION: TO GENERATE AN UNCONTROLLED INTRAUTERINE ENVIRONMENT FOR OBTAINING OFFSPRING CLASSIFIED AS SMALL FOR PREGNANCY AGE

Diabetes was induced at adult life of female rats (approximately at 90 days of age) by beta-cytotoxic agent (Streptozotocin - STZ; Sigma Chemical Company, USA). STZ was dissolved in a citrate buffer $(0.1 \mathrm{~mol} / \mathrm{L}, \mathrm{pH} 4.5)$ and intravenously (i.v.) administered at a dose of $40 \mathrm{mg} / \mathrm{kg}$ body weight. Control rats received (i.v.) only citrate buffer using similar route and administration period. After 72 hours of STZ injection, the diabetic state was confirmed by blood glucose levels $\geq 300 \mathrm{mg} / \mathrm{dL}$ using a conventional glucometer. For nondiabetic rats, the inclusion criteria used was blood glucose levels $\leq 120 \mathrm{mg} / \mathrm{dL}$. Glycemic values were expressed in milligrams per deciliter $(\mathrm{mg} / \mathrm{dL})$ (Volpato et al. 2015a). After one week of diabetes induction or buffer administration (control), all adult female rats were mated to non-diabetic male rats. The offspring was born by spontaneous delivery. Following, the female offspring were separated and classified according to body weight by the mean $\pm 1.0 \mathrm{x}$ standard deviation (SD) considering the mean values of fetal weights of the control group: as appropriate (APA), small (SPA) and large (LPA) for pregnancy age (Volpato et al. 2015b). The female newborns born of the non-diabetic dams and classified as APA were denominated as control group, and the female offspring born of the severe diabetic dams and classified as SPA were included in this study. After newborn classification, only eight newborns (priority to females) were maintained with their mothers from lactation up to weaning period (day 21 postnatal). After weaning, these offspring were maintained until adulthood.

\section{EXPERIMENTAL GROUPS}

The rats were randomly assigned to one of the following groups: - Control $(n=8)$ : SPA female rats not exercised; - Ex1 ( $\mathrm{n}=8)$ : SPA female rats exercised before and during pregnancy according to protocol of Corvino et al. (2015b), and - Ex2 $(\mathrm{n}=8)$ : SPA female rats exercised during pregnancy according to protocol of Corvino et al. (2015a).

EX1- PHYSICAL EXERCISE (SWIMMING PROGRAM) APPLIED PRIOR TO AND DURING PREGNANCY OF INTRAUTERINE GROWTH RESTRICTED (IUGR) RATS (Corvino et al. 2015b)

At around 85 days of life, the rats were daily placed in a cage containing $10 \mathrm{~cm}$ of water for 5 days to familiarize to water. After adaptation period to liquid environment, one month before the mating period, IUGR rats were randomly selected to begin swimming program. The Ex1 adult rats (approximately 90 days) were exposed to swimming program three times per week in a cage containing water at a depth of $40 \mathrm{~cm}$ (sufficient for them to be encouraged to swim) at $32^{\circ} \mathrm{C}$ during 15 min, followed by 15 min of rest and a second 15 min of exercise between 9 - 10h a.m. Throughout the study, the rats were submitted to the swimming program three times a week (on Mondays, Wednesdays and Fridays) before and during entire pregnancy without interruption.

EX2 - PHYSICAL EXERCISE (SWIMMING PROGRAM) APPLIED DURING PREGNANCY OF INTRAUTERINE GROWTH RESTRICTED (IUGR) RATS (Corvino et al. 2015a)

For exercise, it was applied a swimming program according protocol of Corvino et al. (2015a). In the first moment, the rats were daily placed in a cage containing $10 \mathrm{~cm}$ of water for 5 days to familiarize to water. After adaptation period to liquid environment, the rats were placed in a cage containing water at a depth of $40 \mathrm{~cm}$ from day 7 (after embryo implantation) to day 20 (end of pregnancy) of pregnancy. Under these conditions, the rats were submitted to swimming following a detailed protocol (Corvino et al. 2015a, Volpato et al. 2009). 
The control SPA rats were not submitted to swimming training but they were exposed to water before and during pregnancy daily for 15 minutes for 5 days in a cage containing water at a depth of $10 \mathrm{~cm}$ at $31 \pm 1^{\circ} \mathrm{C}$.

\section{MATING AND PREGNANCY}

At 120 days of life, each two rats were mated overnight with one male. The morning on which spermatozoa were found in the vaginal smear was designated pregnancy day 0 . The mating procedure consisted for 15 consecutive days, which comprises approximately three oestral cycle, however nonmated female rats in this period were considered infertile and removed of the study (Dallaqua et al. 2013). In the Ex1 study the rats were submitted to swimming before and during pregnancy, whereas in the Ex2 program the rats were trained after embryonic implantation, i.e., the rats started swimming protocol at day 7 of pregnancy.

\section{EVALUATION OF BIOLOGICAL PARAMETERS} DURING PREGNANCY

At days zero (early pregnancy), seven (embryonic period), 14 (fetal period) and 20 of pregnancy (end of pregnancy - at term pregnancy), maternal body weight and postprandial glycemia were evaluated. Blood samples were obtained by venous puncture of the tail for blood glucose concentrations by conventional glucometer (One Touch Ultra Johnson \& Johnson ${ }^{\circledR}$ ) and the values were presented in $\mathrm{mg} / \mathrm{dL}$, and for serum insulin determination at day 14 of pregnancy by Elisa (Crystal Chemical ELISA Kit 90010 - Rat Insulin Elisa kit).

At the day 17 of pregnancy, oral glucose tolerance test (OGTT) was performed in all the rats to evaluate the presence or absence of glucose intolerance. After fasting for 6 hours, blood glucose levels were verified (time point 0 ). Then, a glucose solution $(200 \mathrm{~g} / \mathrm{L})$ was administered by gavage at a final dose of $2 \mathrm{~g} / \mathrm{kg}$ body weight. Following, the blood samples were obtained from a cut tip tail for glycemic determinations using a glucometer at 30, 60, and 120 minutes ( $\mathrm{min}$ ). Glucose responses during the OGTT were evaluated by estimation of the total area under the curve (AUC), using the trapezoidal method (Sinzato et al. 2012).

\section{BODY WEIGHT CLASSIFICATION OF NEWBORNS}

On day 1 after vaginal delivery, the offspring were weighed. Then, the weight classification of these newborns was performed as previously described in Section "Diabetes induction: To generate an uncontrolled intrauterine environment for obtaining offspring classified as small for pregnancy age".

\section{STATISTICAL ANALYSIS}

For comparison of the mean values between the experimental groups, analysis of variance (ANOVA) followed by Tukey's Multiple Comparison Test were used. The proportions were calculated by the Fisher Exact test. Differences were considered statistically significant when $p<0.05$.

\section{RESULTS}

Table I shows the maternal data during pregnancy. The Ex1 and Ex2 groups did not present alteration on body weight and blood glucose levels compared to control rats. The serum insulin decreased in Ex2 compared to Control and Ex1 animals.

The Ex 2 rats presented reduction in blood glucose levels in the time point 30 and 60 minutes in oral glucose tolerance test (OGTT) compared to Ex1 and Control groups. Additionally, the Ex2 group presented reduced glycemia in the AUC (Figure 1).

The offspring from dams submitted to exercise protocols 1 and 2 presented an increase in the percentage of newborns small for pregnancy age (SPA) and a decrease in the percentage of newborns adequate for pregnancy age (APA) compared to Control group. The offspring from Ex 2 dams also showed decreased percentage of newborns large for 
TABLE I

Maternal data during pregnancy of SPA control, Ex1 and Ex2 rats.

\begin{tabular}{|c|c|c|c|}
\hline \multirow{2}{*}{$\mathrm{n}=8 \mathrm{rats} /$ group } & \multicolumn{3}{|c|}{ Groups } \\
\hline & Control & Ex1 & Ex2 \\
\hline \multicolumn{4}{|l|}{ Body weight (g) } \\
\hline Day 0 & $221.6 \pm 22.1$ & $218.6 \pm 23.1$ & $234.3 \pm 27.7$ \\
\hline Day 7 & $246.8 \pm 27.7$ & $243.80 \pm 28.9$ & $251.3 \pm 29.1$ \\
\hline Day 14 & $269.2 \pm 26.4$ & $255.8 \pm 29.6$ & $267.9 \pm 33.4$ \\
\hline Day 20 & $326.4 \pm 41.1$ & $328.6 \pm 44.5$ & $314.5 \pm 47.9$ \\
\hline \multicolumn{4}{|l|}{ Glycemia (mg/dL) } \\
\hline Day 0 & $100.6 \pm 5.7$ & $104.00 \pm 5.24$ & $102.55 \pm 17.12$ \\
\hline Day 7 & $104.2 \pm 8.1$ & $106.80 \pm 9.85$ & $102.88 \pm 9.59$ \\
\hline Day 14 & $98.2 \pm 3.2$ & $87.00 \pm 3.08$ & $87.33 \pm 2.91$ \\
\hline Day 20 & $82.4 \pm 9.3$ & $80.20 \pm 3.70$ & $82.77 \pm 11.59$ \\
\hline \multicolumn{4}{|l|}{ Serum insulin $(\mathrm{ng} / \mathrm{mL})$} \\
\hline Day 14 & $0.4 \pm 0.1$ & $0.4 \pm 0.1$ & $0.2 \pm 0.1^{* \#}$ \\
\hline
\end{tabular}

Values are expressed as mean \pm standard deviation (SD). ${ }^{*} \mathrm{p}<0.05$ - compared to control rats (ANOVA followed by Tukey's Multiple Comparison Test). ${ }^{*} \mathrm{p}<0.05$ - compared to Ex1 rats (ANOVA followed by Tukey's Multiple Comparison Test).

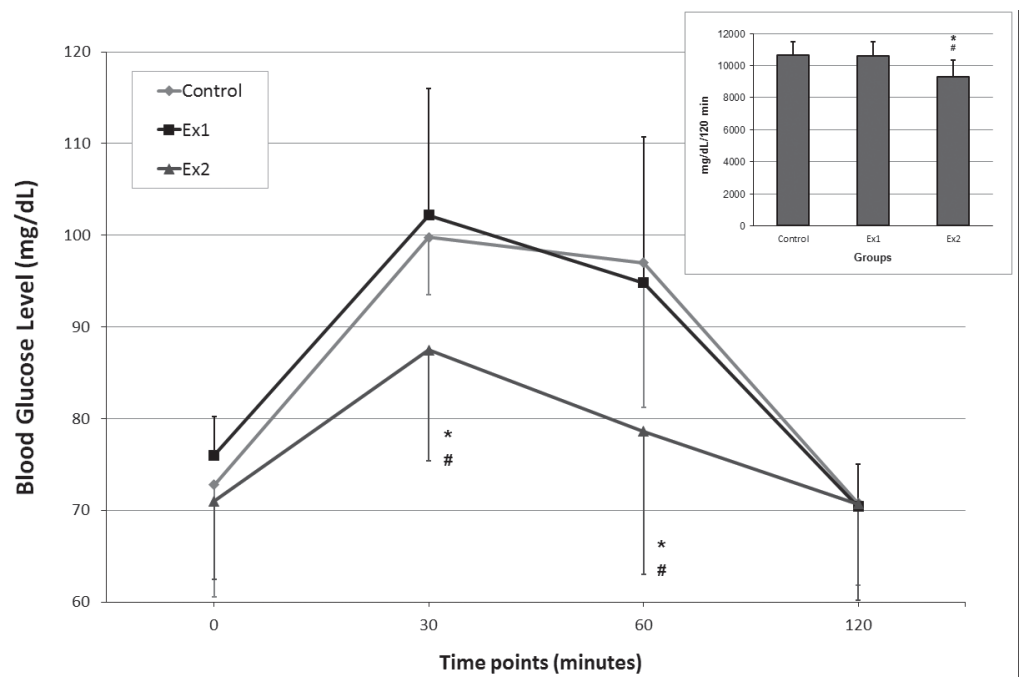

Figure 1 - Oral glucose tolerance test and area under curve from oral glucose tolerance test at day 17 of pregnancy of SPA control, Ex1 and Ex2 groups. Values are expressed as mean \pm standard deviation (SD) with $\mathrm{n}=8$ rats/group. ${ }^{*} \mathrm{p}<0.05$ - compared to control rats (ANOVA followed by Tukey's Multiple Comparison Test). ${ }^{*} \mathrm{p}<0.05$ - compared to Ex1 rats (ANOVA followed by Tukey's Multiple Comparison Test).

pregnancy age (LPA) compared to Control group.

Besides, the offspring of this group presented increased of SPA and decreased APA and LPA newborns compared to Ex1 offspring (Table II).
DISCUSSION

The present study showed both swimming protocols applied to SPA rats did not interfere on body weight and blood glucose levels during pregnancy 
TABLE II

Classification of the body weight gain of newborns from SPA control, Ex1 and Ex2 dams.

\begin{tabular}{cccc}
\hline & \multicolumn{3}{c}{ Groups } \\
\hline & Control & Ex1 & Ex2 \\
\hline SPA (\%) & 11.3 & $34.9^{*}$ & $64.9^{* \#}$ \\
\hline APA $(\%)$ & 75.5 & $49.2^{*}$ & $35.1^{* \#}$ \\
\hline LPA $(\%)$ & 13.2 & 15.9 & $0.0^{* \#}$ \\
\hline
\end{tabular}

Values are expressed as percentage (\%). ${ }^{*} \mathrm{p}<0.05$ - compared to control rats (Fisher Exact Test). ${ }^{\#} \mathrm{p}<0.05$ - compared to Ex1 rats (Fisher Exact Test).

compared to control rats. These results suggest the two models of swimming applied to pregnant rats caused no impairment on weight gain. Osorio et al. (2003) evaluated the chronic effect of exercise during water immersion associated with thermal stress at an intensity of $80 \%$ of maximal workload supported in pregnant and non-pregnant female rats. These authors concluded that pregnant rats gained weight and presented higher glycemia than the nonpregnant group, but no differences in weight gain and blood glucose levels were found in the pregnant groups. Regarding the insulin measurement, the exercise protocol 2 (Ex2) led to reduced levels of this hormone compared to levels of control and Ex1 rats at day 14 of pregnancy. This finding suggests that this status could control insulin resistance of the intrauterine growth restriction (IUGR) animals and corroborates the results of Corvino et al. (2015a), who showed increased insulin sensitivity without glycemic change. The results of swimming practiced an hour a day throughout pregnancy (Ex2) presented beneficial effects in maternal organism and findings on fetal development of rats submitted to two different protocols of swimming are being analyzed and it will presented later. Volpato et al. (2006) also used a similar swimming protocol and demonstrated improvement in maternal results, especially in lipid profile.

We verified that Ex 2 pregnant rats presented a reduction in blood glucose levels in the time points 30 and 60 minutes, i.e., before final test, showing advanced glycemic return. Besides, this experimental group presented reduced glycemia in the AUC after oral glucose tolerance test (OGTT) analyses at day 17 of pregnancy compared to those of control and Ex1 groups. Our findings suggest glucose transporter type 4 (GLUT-4) protein content and glucose transport increase in exercise training. Skeletal muscle has relationship with increased glucose transport capacity, which is caused by the increased GLUT4 protein. This corroborates the evidence that GLUT4 is the major glucose transporter isoform in skeletal muscle (James et al. 1989) and this protein is translocated into the plasma membrane in muscle due to both insulin and exercise actions (Hirshman et al. 1988, Klip and Paquet 1990). Thus, the comparative analysis of experimental protocols showed that the time and period of exercise was enough to change the maternal organism and the exercise of continuous $60 \mathrm{~min} /$ day, 6 days/week ameliorated the enhanced peripheral insulin sensitivity in growth-restricted females.

The analyses of the weight classification of the newborns show that the offspring from dams submitted to both exercise protocols presented an increase in the percentage of newborns classified as small for pregnancy age and a decrease in the percentage of newborns classified as adequate for pregnancy age compared to control newborns. Besides, the offspring from Ex2 dams showed percentage twice higher of newborns small for pregnancy age than Ex1 offspring. Damasceno et al. (2013) verified the exercise during pregnancy, using protocol similar to Ex2 led to IUGR newborn. Evidence suggests that there is no correlation 
between light or moderate intensity exercise and IUGR (Brow 2002, Tomić et al. 2013), but there are studies that have confirmed an association between intense exercise and IUGR (Spinillo et al. 1996, Artal and O'Toole 2003).

Our data suggests that Ex 2 program (swimming applied without breaks, more days a week and without previous training to pregnancy) ameliorated the enhanced peripheral insulin sensitivity in growth-restricted females. However, this protocol employed at pregnancy leads to intrauterine growth restriction. These findings reinforce the need for monitoring of exercise with interdisciplinary and professional discussion involving the intensity, type, period and time of exposure of the applied exercise for women during pregnancy.

\section{ACKNOWLEDGMENTS}

The authors are grateful to staff of the Laboratory of Experimental Research on Gynecology and Obstetrics, Talisia C. Moreto for her excellent animal care and Coordenação de Aperfeiçoamento de Pessoal de Nível Superior (CAPES) for scholarship to Silvana B. Corvino.

\section{REFERENCES}

AERTS L AND VAN ASSCHE FA. 2006. Animal evidence for the transgenerational development of diabetes mellitus. Int J Biochem Cell Biol 38(5-6): 894-903.

ARTAL R AND O'TOOLE M. 2003. Guidelines of the American College of Obstetricians and Gynecologists for exercise during pregnancy and the postpartum period. Br J Sports Med 37(1): 6-12.

BARKER DJP. 1997. Maternal nutrition, fetal nutrition, and disease in later life. Nutrition 13(9): 807-813.

BASSAN H, BASSAN M, PINHASOV A, KARIV N, GILADI E, GOZES I AND HAREL S. 2005. The pregnant spontaneously hypertensive rat as a model of asymmetric intrauterine growth retardation and neurodevelopmental delay. Hypertens Pregnancy 24(3): 201-211.

BROW W. 2002. The benefits of physical activity during pregnancy. J Sci Med Sport 5(1): 37-45.

CORVINO SB, NETTO AO, SINZATO YK, CAMPOS KE, CALDERON IMP, RUDGE MV, VOLPATO GT, ZAMBRANO E AND DAMASCENO DC. $2015 \mathrm{a}$.
Intrauterine growth restricted rats exercised at pregnancy: maternal-fetal repercussions. Reprod Sci 22(8): 991-999.

CORVINO SB, VOLPATO GT, RUDGE MV AND DAMASCENO DC. 2015b. Intrauterine growth restricted rats exercised before and during pregnancy: Maternal and perinatal repercussions. Evid Based Complement Alternat Med 2015: 294850.

DAHRI S, SNOECK A, REUSENS-BILLEN B, REMACLE C AND HOET JJ. 1991. Islet function in offspring of mothers on low-protein diet during gestation. Diabetes 40: 115-120.

DALLAQUA B, SAITO FH, RODRIGUES T, CALDERON IM, RUDGE MV, VOLPATO GT AND DAMASCENO DC. 2013. Azadirachta indica treatment on the congenital malformations of fetuses from rats. J Ethnopharmacol 150(3): 1109-1113.

DAMASCENO DC, SILVA HP, VAZ GF, VASQUES-SILVA FA, CALDERON IM, RUDGE MV, CAMPOS KE AND VOLPATO GT. 2013. Diabetic rats exercised prior to and during pregnancy: maternal reproductive outcome, biochemical profile, and frequency of fetal anomalies. Reprod Sci 20(7): 730-738.

DAMASCENO DC, VOLPATO GT, SINZATO YK, LIMA PH, SOUZA MS, IESSI IL, KISS AC, TAKAKU M, RUDGE MV AND CALDERON IM. 2011. Genotoxicity and fetal abnormality in streptozotocin-induced diabetic rats exposed to cigarette smoke prior to and during pregnancy. Exp Clin Endocrinol Diabetes 119(9): 549-553.

FERNANDEZ-TWINN DS AND OZANNE SE. 2006. Mechanisms by which poor early growth programs type-2 diabetes, obesity and the metabolic syndrome. Phys Behav 88(3): 234-243.

GUZMAN C, CABRERA R, CARDENAS M, LARREA F, NATHANIELSZ PW AND ZAMBRANO E. 2006. Protein restriction during fetal and neonatal development in the rat alters reproductive function and accelerates reproductive ageing in female progeny. J Physiol 572(Pt1): 97-108.

HANSON MA AND GLUCKMAN PD. 2011. Developmental origins of health and disease: moving from biological concepts to interventions and policy. Int J Gynaecol Obstet 7292(11): 60003-60009.

HIRSHMAN MF, WALLBERG-HENRIKSSON H, WARDZALA LJ, HORTON ED AND HORTON ES. 1988. Acute exercise increases the number of plasma membrane glucose transporters in rat skeletal muscle. FEBS Lett 238: 235-239.

JAMES DE, STRUBE M AND MUECKLER M. 1989. Molecular cloning and characterization on an insulinregulatable glucose transporter. Nature Lond 338: 83-87.

KANAKA-GANTENBEIN C. 2010. Fetal origins of adult diabetes. Ann N Y Acad Sci 1205: 99-105.

KIM C. 2010. Gestational diabetes: risks, management, and treatment options. Int J Womens Health 2: 339-251. 
KLIP A AND PAQUET MR. 1990. Glucose transport and glucose transporters in muscle and their metabolic regulation. Diabetes Care 13: 228-243.

NATHANIELSZ PW. 2006. Animal models that elucidate basic principles of the developmental origins of adult diseases. ILAR J 47(1): 73-82.

NYIRENDA MJ, LINDSAY RS, KENYON CJ, BURCHELL A AND SECKL JR. 1998. Glucocorticoid exposure in late gestation permanently programs rat hepatic phosphoenolpyruvate carboxykinase and glucocorticoid receptor expression and causes glucose intolerance in adult offspring. J Clin Invest 101(10): 2174-2181.

OSORIO RA, SILVEIRA VL, MALDJIAN S, MORALES A, CHRISTOFANI JS, RUSSO AK, SILVA AC AND PIÇARRO IC. 2003. Swimming of pregnant rats at different water temperatures. Comp Biochem Physiol A Mol Integr Physiol 135(4): 605-611.

RAVELLI AC, VAN DER MEULEN JH, OSMOND C, BARKER DJ AND BLEKER OP. 1999. Obesity at the age of $50 \mathrm{y}$ in men and women exposed to famine prenatally. Am J Clin Nutr 70(5): 811-816.

ROSEBOOM TJ, VAN DER MEULEN JH, RAVELLI AC, VAN MONTFRANS GA, OSMOND C, BARKER DJ AND BLEKER OP. 1999. Blood pressure in adults after prenatal exposure to famine. J Hypertens 17(3): 325-330.

SIMMONS RA, TEMPLETON LJ AND GERTZ SJ. 2001. Intrauterine growth retardation leads to the development of Type 2 diabetes in the rat. Diabetes 50(10): 2279-2286.

SINZATO YK, VOLPATO GT, IESSI IL, BUENO A, CALDERON IM, RUDGE MV AND DAMASCENO DC. 2012. Neonatally induced mild diabetes in rats and its effect on maternal, placental, and fetal parameters. Exp Diabetes Res 2012: 108163.

SPINILLO A, CAPUZZO E, BALTARO F, PIAZZI G, INCOLA S AND IASCI A. 1996. The effect of work activity in pregnancy on the risk of fetal growth retardation. Acta Obstet Gynecol Scand 75(6): 531-535.
TOMIĆ V, SPORIŠ G, TOMIĆ J, MILANOVIĆ Z, ZIGMUNDOVAC-KLAIĆ D AND PANTELIĆ S. 2013. The effect of maternal exercise during pregnancy on abnormal fetal growth. Croat Med J 54(4): 362-368.

TRAN M, GALLO LA, JEFFERIES AJ, MORITZ KM AND WLODEK ME. 2013. Transgenerational metabolic outcomes associated with uteroplacental insufficiency. J Endocrinol 217: 105-118.

VOLPATO GT, CALDERON IM, SINZATO S, CAMPOS KE, RUDGE MV AND DAMASCENO DC. 2011. Effect of Morus nigra aqueous extract treatment on the maternalfetal outcome, oxidative stress status and lipid profile of streptozotocin-induced diabetic rats. J Ethnopharmacol 138(3): 691-696.

VOLPATO GT, DAMASCENO DC, CAMPOS KE, ROCHA R, RUDGE MV AND CALDERON IM. 2006. Avaliação do efeito do exercício físico no metabolismo de ratas diabéticas prenhes. Rev Bras Med Esp 12(5): 229-233.

VOLPATO GT, DAMASCENO DC, KEMPINAS WG, RUDGE MV AND CALDERON IM. 2009. Effect of exercise on the reproductive outcome and fetal development of diabetic rats. Reprod Biomed Online 19(6): 852-858.

VOLPATO GT, DAMASCENO DC, SINZATO YK, RIBEIRO VM, RUDGE MV AND CALDERON IM. 2015a. Oxidative stress status and placental implications in diabetic rats undergoing swimming exercise after embryonic implantation. Reprod Sci 22(5): 602-608.

VOLPATO GT, FRANCIA-FARJE LAD, DAMASCENO DC, OLIVEIRA RV, HIRUMA-LIMA CA AND KEMPINAS WG. 2015b. Effect of essential oil from Citrus aurantium in maternal reproductive outcome and fetal anomaly frequency in rats. An Acad Bras Cienc 87: 407-415.

WOLF G. 2003. Adult type 2 diabetes induced by intrauterine growth retardation. Nutr Rev 61(5 Pt 1): 176-179.

ZAMBRANO E. 2009. The transgenerational mechanisms in developmental programming of metabolic diseases. Rev Invest Clin 1(1): 41-52. 